\title{
Electron generation in water induced by magnetic effect and its impact on dissolved oxygen concentration
}

\author{
Augustine Chung Wei Yap ${ }^{1}$, Hwang Sheng Lee ${ }^{1,2^{*}} \mathbb{D}$, Joo Ling Loo ${ }^{3}$ and Nuruol Syuhadaa Mohd ${ }^{4}$
}

\begin{abstract}
$\mathrm{pH}$, oxidation-reduction potential (ORP) and dissolved oxygen (DO) concentration are important parameters in water quality surveillance and treatment. The changes of these parameters are associated with electron density in water. Several techniques including electrolysis and catalysis which require redox reactions and electron exchange are employed to improve these parameters. In recent years, studies reported that magnetic effects can impart considerable changes on the $\mathrm{pH}, \mathrm{ORP}$ and $\mathrm{DO}$ concentration of water. However, the correlation between electron density and magnetic effects on these parameters has yet to be disclosed despite the fact that increased electron density in water could improve water's reductive properties, heat capacity and hydrogen bonding characteristics. In this study, the magnetic effects on pH, ORP and DO concentration were investigated using different magnets arrangements and water flow rates based on reversed electric motor principle. Results showed that the improvement of pH, ORP and DO concentration from 5.40-5.42 to 5.58-5.62 (+ 3.5\%), 392 to $365 \mathrm{mV}(-6.9 \%)$, and 7.30 to $7.71 \mathrm{mg} \mathrm{L}^{-1}(+5.6 \%)$, respectively were achieved using combined variables of non-reversed polarity magnet arrangement (1000-1500 G magnetic strength) and water flow rate of $0.1-0.5 \mathrm{~mL} \mathrm{~s}^{-1}$. Such decrement in ORP value also corresponded to $8.0 \times 10^{13}$ number of electron generation in water. Furthermore, Raman analysis revealed that magnetic effect could strengthen the intermolecular hydrogen bonding of water molecules and favor formation of smaller water clusters. The findings of this study could contribute to potential applications in aquaculture, water quality control and treatment of cancer attributed to free radical induced-oxidative stress.
\end{abstract}

Keywords: Electron density, Dissolved oxygen concentration, Magnetic effect, Reversed electric motor principle, Free radical, Water quality parameters

\section{Introduction}

Water quality is important to safeguard water security and to sustain livelihoods of all living organisms on earth. It is determined by several water parameters, for examples $\mathrm{pH}$, oxidation-reduction potential (ORP) and dissolved oxygen (DO) concentration, which are essential in water quality surveillances and water treatment processes $[1,2]$. The measurement of these parameters

\footnotetext{
*Correspondence: leehs@utar.edu.my

'Department of Mechanical and Material Engineering, Universiti Tunku Abdul Rahman, 43000 Kajang, Malaysia

${ }^{2}$ Centre for Photonics and Advanced Materials Research, Universiti Tunku

Abdul Rahman, 43000 Kajang, Malaysia

Full list of author information is available at the end of the article
}

is driven by electron density in water. For examples, $\mathrm{pH}$ and ORP measurements are correlated due to electron exchange generating a potential difference across an electrochemical cell based on the hydrogen ion concentration $(\mathrm{pH})$ and potential value $(E)$ [3]. DO concentration is the measurement of molecular oxygen dissolved in water. Likewise, DO measuring technique using polarographic membrane DO sensor involves redox reaction and potential voltage in order to provide an accurate DO value $[4,5]$. Such sensor comprises two electrodes immersed in an electrolyte into which the $\mathrm{O}_{2}$ in water sample diffuses through the membrane. Electrons flow in the electrode then reduces the $\mathrm{O}_{2}$ into

(c) The Author(s). 2021 Open Access This article is licensed under a Creative Commons Attribution 4.0 International License, which permits use, sharing, adaptation, distribution and reproduction in any medium or format, as long as you give appropriate credit to the original author(s) and the source, provide a link to the Creative Commons licence, and indicate if changes were made. The images or other third party material in this article are included in the article's Creative Commons licence, unless indicated otherwise in a credit line to the material. If material is not included in the article's Creative Commons licence and your intended use is not permitted by statutory regulation or exceeds the permitted use, you will need to obtain permission directly from the copyright holder. To view a copy of this licence, visit http://creativecommons.org/licenses/by/4.0/. 
hydroxide ions. This will induce a potential which is proportional to the concentration of $\mathrm{OH}^{-}$ions. As a result, DO concentration can be measured and displayed by the meter. Therefore, these measurement principles evidence that electron density is important in determining the $\mathrm{pH}, \mathrm{ORP}$ and $\mathrm{DO}$ concentration.

Conventional approaches using physical and chemical methods are employed to improve $\mathrm{pH}$, ORP and DO concentration. These methods include advanced oxidation process, catalysis, electrolysis, distillation and reverse osmosis [6]. For example, electrolysis works by introducing redox reaction through electron exchange mechanisms across two electrodes. In this process, $\mathrm{pH}$, ORP and oxygen concentration are changed based on the reduction of $\mathrm{O}_{2}$ and oxidation of $\mathrm{H}_{2}$ as shown in Eqs. (1) and (2), respectively [7].

$$
\begin{aligned}
& \mathrm{O}_{2}+4 \mathrm{H}^{+}+4 \mathrm{e}^{-} \rightarrow 2 \mathrm{H}_{2} \mathrm{O} \\
& \mathrm{H}_{2} \rightarrow 2 \mathrm{H}^{+}+2 \mathrm{e}^{-}
\end{aligned}
$$

On the other hand, several studies [8-11] also reported that magnetic effect can change the $\mathrm{pH}$, ORP and DO concentration of water. This magnetic effect can be originated from electromagnets or permanent magnets. For instance, magnetic effect with average intensity of $1000-2000 \mathrm{G}$ could increase $\mathrm{pH}$ and DO concentration, while also decrease the ORP. Recently, Lee et al. [8] reported that magnetic effect can increase the electron density and DO concentration based on reversed electric motor principle. The finding showed that $\mathrm{pH}$, ORP, DO concentrations in distilled water were changed from 5.14 to 5.54 (+ $7.8 \%), 461$ to $367 \mathrm{mV}$ (-20.4\%), and 6.68 to $6.90 \mathrm{mg}$ $\mathrm{L}^{-1}(+3.3 \%)$, respectively when electron is generated in water due to mechanical motion of water intersecting with the magnetic effect at a perpendicular angle.

There have been several works that report the effects of electron generation on water properties. Chen et al. [12] investigated the properties of plasmonic activated water that were attracted to hot electron. Such 'electron-doped' water possessed several unique properties such as reduced hydrogen bonds, lower heat capacity, shorter freezing time, and stronger reductive activity. Moreover, the increase of electron density in water that promotes redox mechanism and electron transfer is promising as this contributes many applications in different fields, for examples deoxyribonucleic acid damage, disease treatment and wastewater contaminant remediation [13-18].

While the magnetic effects on $\mathrm{pH}, \mathrm{ORP}$, and DO concentration of water have been previously reported, they were usually inferred based on Lorentz Force theory as well as water cluster and hydrogen bonding characteristics [19-21]. One scope that has not been thoroughly investigated is the correlation of the magnetic effect with electron generation in water which can lead to the improvement of DO concentration. Therefore, this study employs a natural and facile method using permanent magnets to co-generate electron and oxygen in water based on reversed electric motor principle. In order to corroborate the correlation between electron generation and DO concentration, a systematic investigation on water magnetization process through the analyses of water parameters such as $\mathrm{pH}, \mathrm{ORP}$ and $\mathrm{DO}$ concentration was performed under different magnets arrangements and water flow rates. The number of electron generation was calculated through Nernst equation. In addition, the magnetized water was characterized using Raman spectroscopy to indicate the magnetization effect on water properties, for examples, hydrogen bond and water cluster characteristics, which can provide new insights into prospective water science and molecular investigations. Such correlation of electron generation and DO concentration improvement under the influence of magnetic field is essential as it reveals the potential of naturally generating electron and oxygen concurrently from water source without using electricity, unlike electrolysis. With the coexistence of electron and oxygen in water, this green technology can be used in environmental applications such as water treatment and wastewater contaminant remediation, as well as in medical applications including free radical induced-diseases treatment.

\section{Materials and methods}

Deionized (DI) water was used as the water source for the magnetization process in this study. DI water was produced from Milli-Q Academic Ultrapure (Type 1) Water Purification System (Merck Millipore, USA). The $\mathrm{pH}, \mathrm{ORP}$ and DO concentration of water were measured using STPURE $\mathrm{pH}$ electrode (Ohaus), ORP electrode (Hanna Instruments) and optical rugged DO probe (Eutech, Thermo Scientific), respectively. Magnetic effect between 1000 and $1500 \mathrm{G}$ was generated from permanent magnets.

\section{Design of water magnetization system}

A water magnetization system was designed as shown in the schematic diagram (Fig. 1). The $\mathrm{pH}$, ORP and DO concentration of $100 \mathrm{~mL}$ water were measured before and after magnetization. The magnetic effects on water parameters were investigated for variables such as arrangements of permanent magnets and water flow rates. Figure 2 shows the magnets 


\section{Permanent magnets}

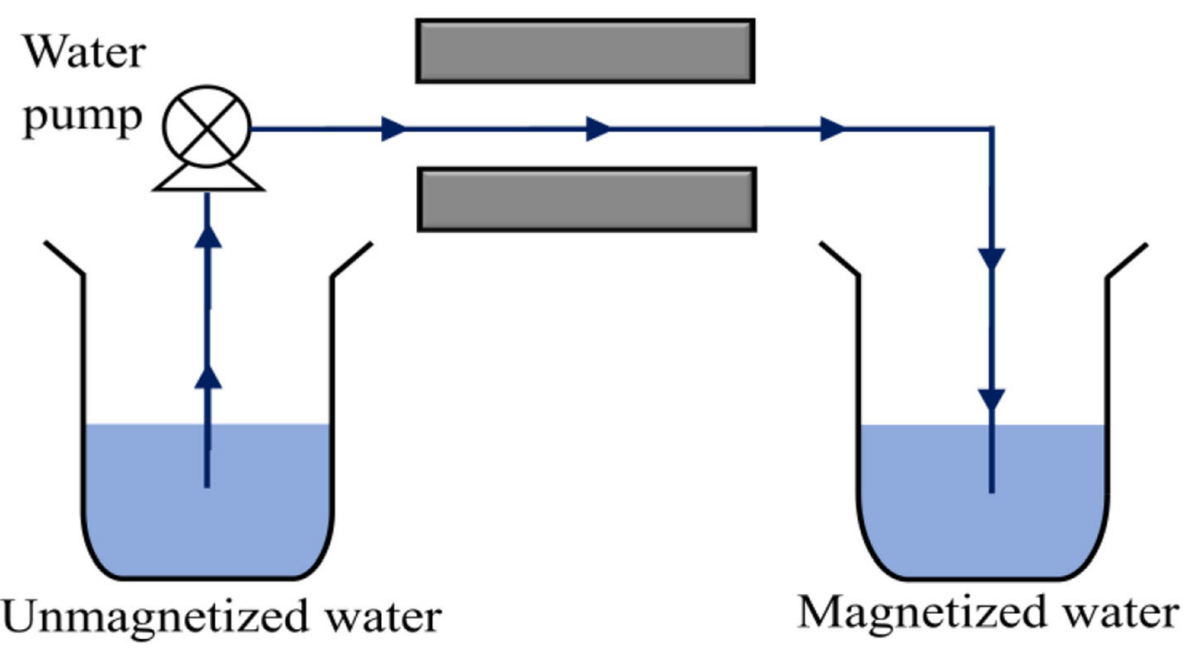

Fig. 1 The flow of water through magnetic effect

arrangements while Table 1 summarizes the variables and their ranges. Control experiment was performed by flowing the water in the absence of magnetic effect in order to validate the influence of magnetic effects on the water parameters. The changes of water parameters were calculated and reported as percentage change based on Eq. (3).

$$
\text { Percentage change }(\%)=\frac{V_{a}-V_{b}}{V_{b}} \times 100 \%
$$

where $V_{\mathrm{a}}$ and $V_{\mathrm{b}}$ represent the measured values of water parameters after flowing and before flowing, respectively. A positive percentage change signifies increment of

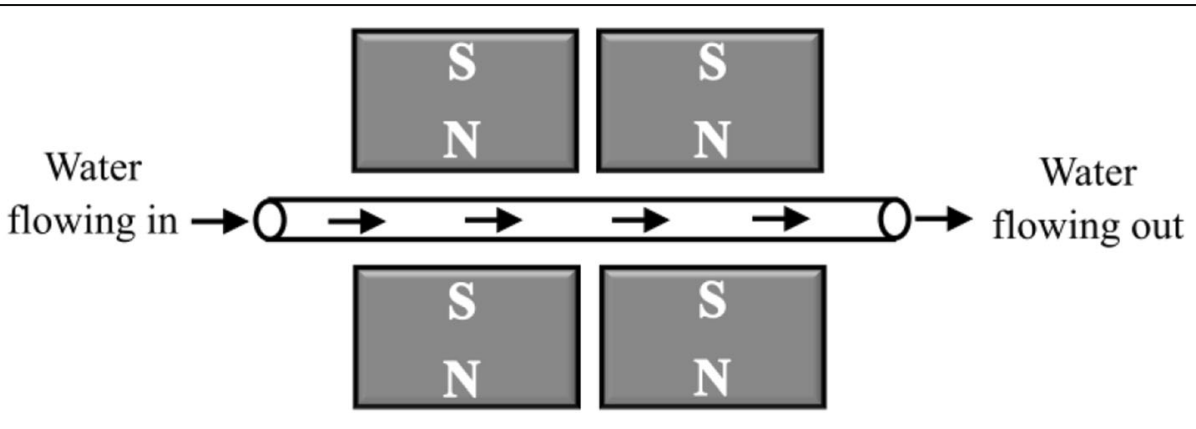

(a)

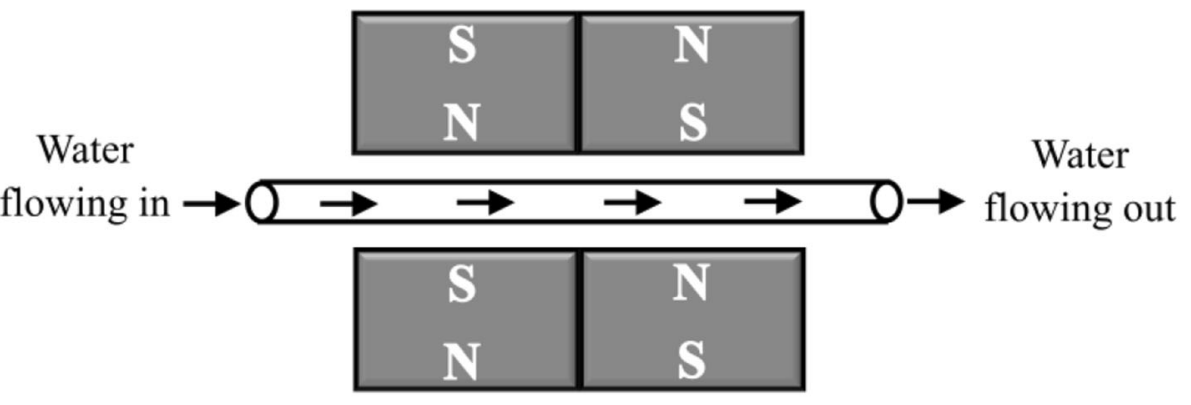

(b)

Fig. 2 The magnets arrangements used in the study: a non-reversed polarity; and $\mathbf{b}$ reversed polarity 
Table 1 Experimental variables for the influence of magnetic effect on water parameters

\begin{tabular}{ll}
\hline Variables & Range \\
\hline Water flow rate & Low: $0.1-0.5 \mathrm{~mL} \mathrm{~s}^{-1} ;$ \\
& Medium: $1.0-1.5 \mathrm{~mL} \mathrm{~s}^{-1} ;$ \\
& High: $2.0-2.5 \mathrm{~mL} \mathrm{~s}{ }^{-1}$ \\
Arrangement of permanent magnets & Non-reversed polarity; \\
& Reversed polarity \\
\hline
\end{tabular}

value whereas a negative percentage change signifies decrement of value.

\section{Characterization of magnetized water using Raman spectroscopy}

Both unmagnetized and magnetized water were analyzed by using confocal Raman spectrometer (Renishaw inVia ${ }^{\mathrm{TM}}$ ) integrated with a confocal Raman microscope. The light source used was green laser with excitation wavelength of $532 \mathrm{~nm}$. Laser power was fixed at 5\%. Approximately $0.5-1.0 \mathrm{~mL}$ of water droplet was placed on top of a silicon disk substrate on the microscope stage. The light source was focused onto the water droplet through a $50 \times$ long distance lens.

\section{Results and discussion}

\section{Effect of magnets arrangements on water parameters}

The water flowed under non-reversed polarity magnets arrangement at flow rate of $0.1-0.5 \mathrm{~mL} \mathrm{~s}^{-1}$ showed an overall better improvement of $\mathrm{pH}$, ORP and DO concentration in comparison to the flow under reversed polarity magnets arrangement. The percentage changes of $\mathrm{pH}$, ORP and DO concentration for this arrangement were + $3.5,-4.2$ and $+9.5 \%$, respectively (Fig. 3 ; Table S1). On the contrary, the reversed polarity magnets arrangement yielded smaller percentage changes, which were +2.5 , -
3.0 and $+5.0 \%$, respectively (Fig. 3 ; Table S1). The magnetic effect generated from non-reversed magnetic poles was almost uniform, as compared to its reversed counterpart which generated a highly discontinuous field [22, 23]. Furthermore, magnets with reversed and nonreversed configurations also corresponded to different magnetic field waveforms, with the latter having more homogenous waveform [24]. Nonetheless, Alabi et al. [25] claimed that the purpose of using any magnetic configuration was to generate a uniform magnetic field within the passage of water flow. Hence, most essentially, the orientation of magnets should be in such a way that the water flow is always perpendicular $\left(90^{\circ}\right)$ to the magnetic field lines [26].

\section{Effect of flow rate on water parameters}

The results in Fig. 4 and Table S2 revealed that when water flowed through magnetic effect at the lowest flow rate, which was $0.1-0.5 \mathrm{~mL} \mathrm{~s}^{-1}$, a better improvement of $\mathrm{pH}$, ORP and DO concentration was achieved. In this case, the percentage changes of $\mathrm{pH}$, ORP, and DO concentration after magnetization amounted to $+3.5,-6.9$ and $+5.6 \%$, respectively. When flow rate increased, the percentage changes of water parameters decreased. As shown in Fig. 4, when flow rate increased further to 1.0$1.5 \mathrm{~mL} \mathrm{~s}^{-1}$, the percentage changes decreased to +2.6 , 1.8 and $+4.8 \%$, respectively. Subsequently, when the highest flow rate $\left(2.0-2.5 \mathrm{~mL} \mathrm{~s}^{-1}\right)$ was reached, the percentage changes recorded the lowest, which amounted to $+0.92,-1.3$ and $+2.9 \%$, respectively. Similar findings were reported in the study conducted by Kadhim and Al-Rufaye [27] where the average change in water parameters such as $\mathrm{pH}$, ORP and electrical conductivity of well water decreased from $+1,+16$ and $+3 \%$ to $0,+1$ and $+1 \%$, respectively when flow rate increased from 0.1 to $1 \mathrm{~L} \mathrm{~s}^{-1}$. Besides, the magnetization effect was reported

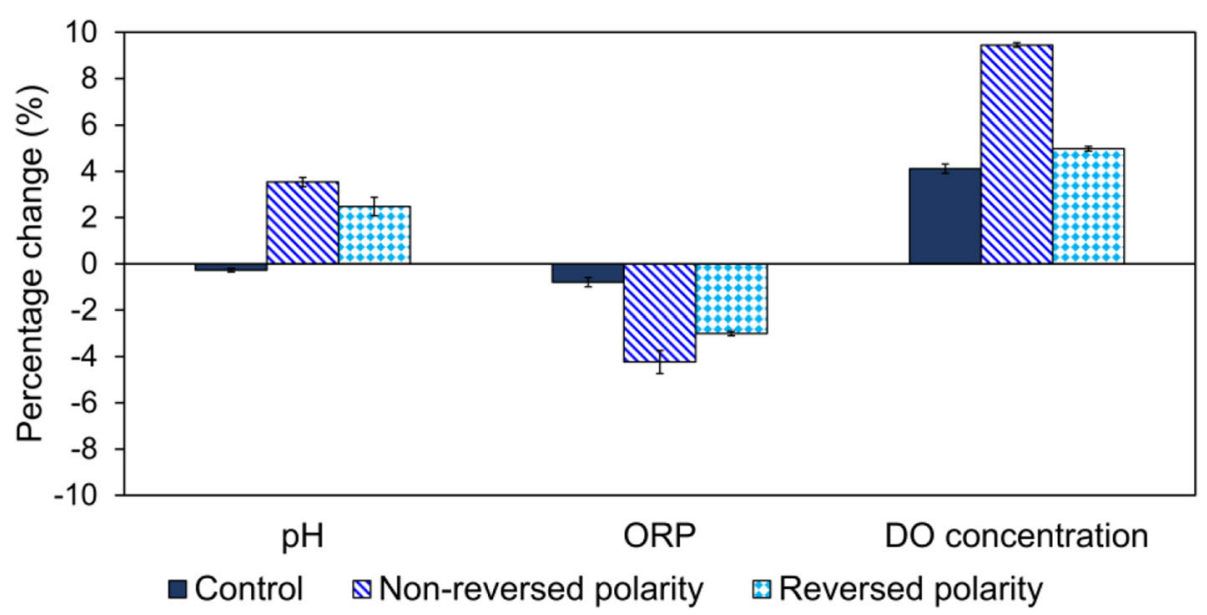

Fig. 3 Results of pH, ORP and DO concentration of water after magnetization by using different magnets arrangements 


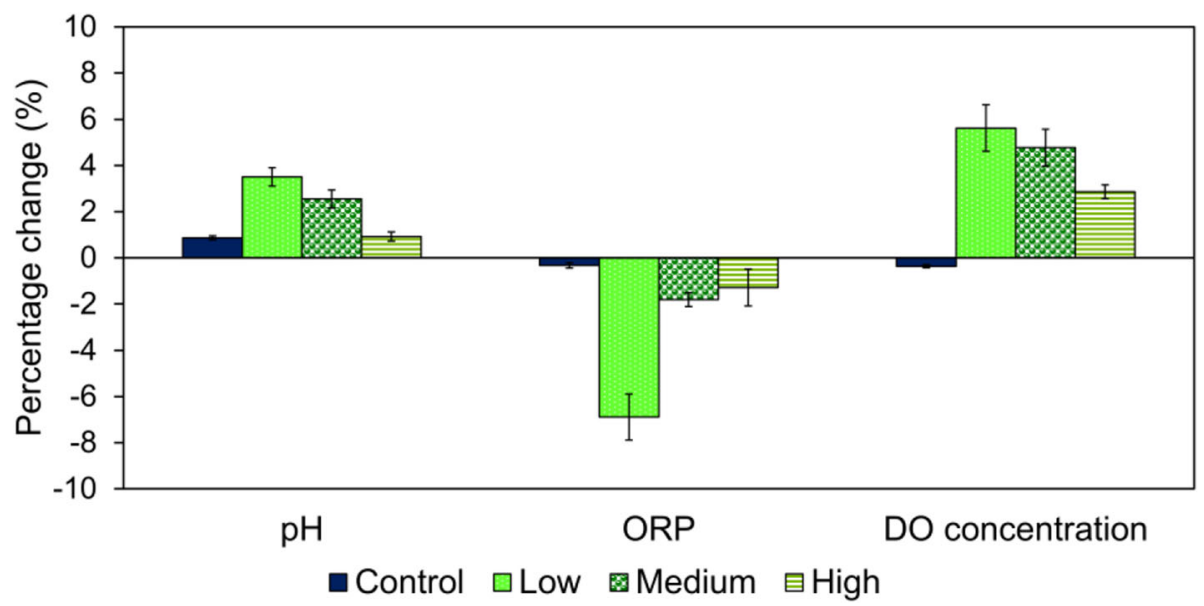

Fig. 4 Results of pH, ORP and DO concentration of water after magnetization at low $\left(0.1-0.5 \mathrm{~mL} \mathrm{~s}^{-1}\right)$, medium (1.0-1.5 $\left.\mathrm{mL} \mathrm{s}^{-1}\right)$ and high $(2.0-2.5$ $\mathrm{mL} \mathrm{s}^{-1}$ ) flow rate, respectively

to increase at low flow rate, indicating a longer exposure time of water to magnetic effect [28]. Therefore, these results can show that lower flow rate increases the exposure time of water to magnetic effect, leading to the overall improvement of water parameters.

\section{Correlation of $\mathrm{pH}$ and ORP calculations}

Typically, from the experimental findings, when water flowed through magnetic effect, its $\mathrm{pH}$ and DO concentration increased whereas its ORP decreased. This trend could be explained through reversed electric motor principle. Primarily, this principle is referenced from the electric motor theory [29] such that when current passes through a conductor coil in a magnetic field, a torque (mechanical force) will be generated which in turn moves the coil. As a result of current passing through the conductor coil, the electron will flow, hence producing electricity. The reversed electric motor principle is precisely the reversed process of electric motor theory, which can also be known as the electric generator principle [30]. In the context of water magnetization, the principle imparts the following attributes to the parameters as represented in Eqs. (4) and (5), respectively [31].

$$
\begin{aligned}
& \mathrm{H}_{2} \mathrm{O} \leftrightharpoons \mathrm{H}^{+}+\mathrm{OH}^{-} \\
& 4 \mathrm{OH}^{-} \leftrightharpoons 2 \mathrm{H}_{2} \mathrm{O}+\mathrm{O}_{2}+4 \mathrm{e}^{-}
\end{aligned}
$$

Water molecules ionize to form $\mathrm{H}^{+}$and $\mathrm{OH}^{-}$ions under equilibrium condition based on Eq. (4).

1. Current is induced when magnetic effect is disrupted by the mechanical motion of water flow, which is flowing in the direction perpendicular to the magnetic field.

2. The induced current will promote flow of electron.
3. The generated electron has the tendency to bind with $\mathrm{H}^{+}$cation from ionized water molecule through metastable bonding.

4. Consequently, $\mathrm{pH}$ of water increases and the concentration of $\mathrm{OH}^{-}$anion also increases simultaneously.

5. When there is excess $\mathrm{OH}^{-}$anion due to $\mathrm{pH}$ increment, the chemical equilibrium is disturbed. As a result, subsequent oxidation of $\mathrm{OH}^{-}$anion occurs to form $\mathrm{O}_{2}, \mathrm{H}_{2} \mathrm{O}$ and electron (Eq. (5)) in order to restore chemical equilibrium based on Le Chatelier's principle [32, 33].

The presence of electron in water was indicated by the ORP measurement. The principle of ORP measurement states that when ORP value of water decreases, it signifies the increase of electron density in water. This study highlights the significance of $\mathrm{pH}$ and ORP due to the reversed electric motor effect. A correlation between $\mathrm{pH}$ and ORP can be determined by using the Nernst equation [34] as shown in Eq. (6).

$$
E=E^{\circ}+\frac{2.3 R T}{n F} \log \left[\mathrm{H}^{+}\right]
$$

where $E, E^{\circ}, R, T, n, F$ and $\left[\mathrm{H}^{+}\right]$represent the measured potential (ORP value) in $\mathrm{V}$, the standard potential value in $\mathrm{V}$, gas constant (8.31) in $\mathrm{J} \mathrm{mol}^{-1} \mathrm{~K}^{-1}$, absolute temperature in $\mathrm{K}$, stoichiometric number of exchanged electrons in the reaction, Faraday's constant (96490) in $\mathrm{C} \mathrm{mol}{ }^{-1}$ and hydrogen ions concentration, respectively. The redox activity, in terms of $E$ value can be measured by the ORP sensor using the analogy of electrochemical cell when a potential difference (electron transfer) occurs between the inert or indicating electrode (usually 
platinum) and the silver/silver chloride $(\mathrm{Ag} / \mathrm{AgCl})$ reference electrode. In this study, two possible half reactions of redox reactions can be assumed, which are the reduction of $\mathrm{AgCl}$ [35] and oxidation of $\mathrm{OH}^{-}$[36]. They are shown in Eqs. (7) and (8), respectively.

$$
\begin{aligned}
& 4 \mathrm{AgCl}+4 \mathrm{e}^{-} \leftrightharpoons 4 \mathrm{Ag}+4 \mathrm{Cl}^{-} \\
& 4 \mathrm{OH}^{-} \leftrightharpoons 2 \mathrm{H}_{2} \mathrm{O}+\mathrm{O}_{2}+4 \mathrm{e}^{-}
\end{aligned}
$$

Based on electrochemistry theory and the standard electrode potential values [35, 36], the reduction of $\mathrm{AgCl}$ in the ORP sensor represents the cathode with $E^{\circ}=0.222$ $\mathrm{V}$, whereas the oxidation of $\mathrm{OH}^{-}$from water represents the anode with $E^{\circ}=-0.401 \mathrm{~V}$. Thus, the overall $E^{\circ}$ of the cell $\left(E_{\text {cell }}^{\circ}\right)$ is $0.623 \mathrm{~V}$, which is calculated based on Eq. (9) [37].

$$
E_{\text {cell }}^{o}=E_{\text {cathode }}^{\circ}-E_{\text {anode }}^{o}
$$

By using $E^{\circ}=0.623 \mathrm{~V}$, the experimental and theoretical $E$ values can be calculated based on the measured $\mathrm{pH}$ values of water in this study using Eq. (6). By assumption, for every $\mathrm{pH}$ increment by $1.00, E$ value or ORP value would decrease by $0.015 \mathrm{~V}$ (Table S3; Fig. S1).

\section{Electron generation in water due to magnetic effect}

From the $\mathrm{pH}$ and ORP correlation calculation, it is also possible to estimate the number of electrons generated in water. The estimated number of electrons generated in the control and magnetization experiments based on $\mathrm{pH}$ and ORP measurements were calculated as shown in Table S4, and the results summarized in Table 2. The obtained results are based on the data from optimized magnetization variables, which is non-reversed polarity magnets arrangement combined with the lowest flow rate $\left(0.1-0.5 \mathrm{~mL} \mathrm{~s}^{-1}\right)$.

Table 2 reveals that once water flowed through magnetic effect, $\mathrm{pH}$ and ORP values are changed accordingly. The number of electrons could increase from $1.6 \times 10^{14}$ to $2.4 \times 10^{14}$, as compared to control which was from $1.5 \times 10^{14}$ to $1.7 \times 10^{14}$ when there was no magnetic effect. Meanwhile, these data imply that both
$\mathrm{pH}$ increment and ORP decrement are associated with the number of electrons generated in water. Subsequently, when water is magnetized, the number of electron generation could amount to $8.0 \times 10^{13}$, as compared to the control which could amount to only $2.0 \times 10^{13}$. Therefore, this evidences that $\mathrm{pH}$ increment can lead to remarkable increase in electron density and DO concentration in water due to magnetic effect.

\section{Raman spectral analysis}

Figure 5a shows the Raman spectra for unmagnetized and magnetized water in the wavenumber of $2600-4000$ $\mathrm{cm}^{-1}$. Both the symmetric and asymmetric $\mathrm{OH}$ stretching vibrations of water are located between 2900 and $3700 \mathrm{~cm}^{-1}$.

Li et al. [38] stated that the typical Raman spectra of water consists of a peak around $3400 \mathrm{~cm}^{-1}$, an intense shoulder around $3200 \mathrm{~cm}^{-1}$ and a weak shoulder near $3600 \mathrm{~cm}^{-1}$. These typical characteristics are observed in the Raman spectra. As seen in Fig. 5a, magnetized water has an overall greater intensities of the Raman peak and the shoulders than that of unmagnetized water, which aligns with the findings of Pang and Deng [39]. This phenomenon was associated to the alteration in water molecular structures and clusters, as well as the transition of valence, bonded and inner-layer electrons due to magnetic effect [39]. The higher electron density in water generated a higher Raman intensity due to higher electronic transition upon excitation by the electromagnetic irradiation (Raman laser) on water [40].

In addition, a higher Raman $\mathrm{OH}$ stretching vibration intensity of water could be associated with stronger intermolecular hydrogen bonds of water [41]. This aligns with the findings of Toledo et al. [19] whereby magnetic effect weakens intra cluster hydrogen bonds of water, which promotes smaller water clusters formation with strong inter cluster hydrogen bonds. Based on the finding of Chen et al. [12], electron played a significant role in the transformation of water clusters and alteration of hydrogen bonds. In particular, water with reduced hydrogen bonds via electron-induced mechanism had a

Table 2 Estimated number of electron generated in water with magnetic effect based on $\mathrm{pH}$ and ORP

\begin{tabular}{llll}
\hline & Initial value & After flowing & Delta $(\boldsymbol{\Delta})$ value \\
\hline Control experiment & & & 0.04 \\
$\mathrm{pH}$ & 5.40 & 5.44 & -2 \\
$\mathrm{ORP}(\mathrm{mV})$ & 403 & 401 & $2.0 \times 10^{13}$ \\
Estimated number of electron & $1.5 \times 10^{14}$ & $1.7 \times 10^{14}$ & \\
Magnetization experiment & & & 0.19 \\
$\mathrm{pH}$ & 5.41 & 5.60 & -27 \\
ORP (mV) & 392 & 365 & $8.0 \times 10^{13}$ \\
Estimated number of electron & $1.6 \times 10^{14}$ & $2.4 \times 10^{14}$ & \\
\hline
\end{tabular}



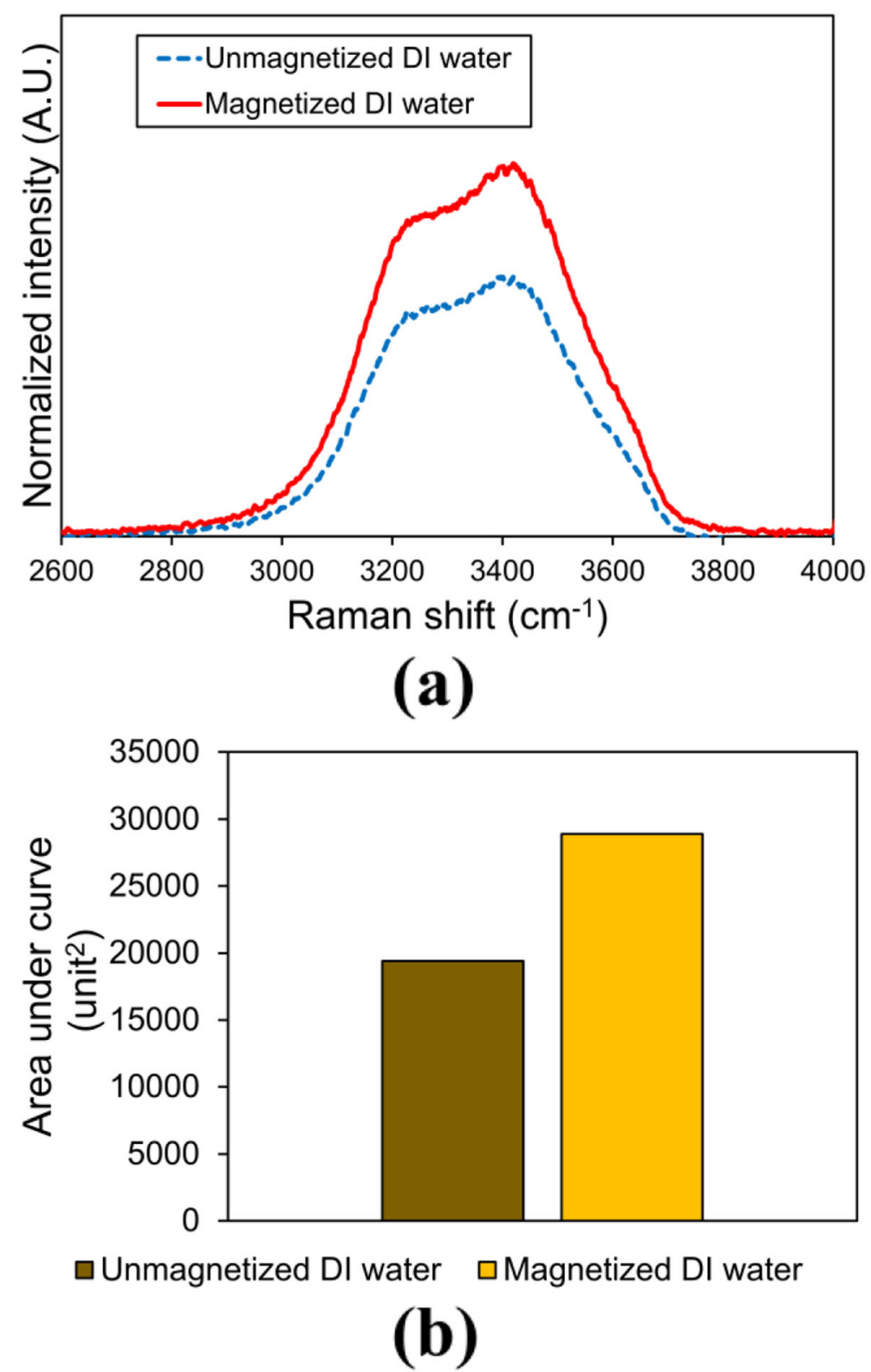

Fig. 5 a Raman spectra (from 2600 to $4000 \mathrm{~cm}^{-1}$ ) for unmagnetized DI water, and magnetized DI water produced by water flowing at flow rate of $0.1-0.5 \mathrm{~mL} \mathrm{~s}^{-1}$; and $\mathbf{b}$ Computed areas under curve for the unmagnetized DI water and magnetized DI water spectra, respectively

greater peak area of Raman spectra compared to normal DI water. Therefore, the finding in this study, which showed that magnetized water had a greater Raman peak area compared to unmagnetized water (Fig. 5b), aligned with literature findings in terms of generating water with increased electron density, reduced hydrogen bonding and smaller cluster size.

\section{Implications of study}

The electron density and DO concentration increment in water can suggest potential applications in essential water-related industries, particularly in disease control.
For examples, most recent literatures have highlighted that free radical damage could have contributed to novel Coronavirus SARS-CoV - 2 infections that cause the severe Coronavirus pandemic alongside other respiratory infection such as the severe acute respiratory syndrome [42]. Besides, cancer can also be attributed to free radical damage induced by reactive oxygen species [43]. These free radical species in body lack electron which makes them highly reactive. As a result, cells are susceptible to oxidative stress. Higher electron density water may be able to counteract the oxidative stress when free radical species scavenge electron from water. In addition, since 
this study also substantiates DO increment in water due to magnetic effect, it can also be recommended for the treatment of cancers developed from hypoxia (an environment with decreased oxygen level) [44], which is conventionally treated with oxygen nanoshuttles in clinical study [45].

\section{Conclusions}

Magnetic effect increased $\mathrm{pH}$ and $\mathrm{DO}$ concentration while decreased the ORP of water. The combined variables of non-reversed polarity magnets arrangement and the lowest flow rate $\left(0.1-0.5 \mathrm{~mL} \mathrm{~s}^{-1}\right)$ led to $\mathrm{pH}$ and $\mathrm{DO}$ concentration increment by 3.5 and $5.6 \%$, respectively and ORP decrement by $6.9 \%$. These indicate that magnetic effect increases electron density and DO concentration in water. The ORP decrement corresponded to $8.0 \times 10^{13}$ number of electron generation in water. Meanwhile, Raman characterization shows that magnetic effect strengthens intermolecular hydrogen bonding of water molecules and promotes smaller water clusters formation. The electron generation and DO concentration increment in water may be regarded as potential applications in treatment of infectious diseases induced by free radical species.

\section{Supplementary Information}

The online version contains supplementary material available at https://doi. org/10.1186/s42834-021-00080-0.

\section{Additional file 1.}

\section{Acknowledgements}

This research was supported by Ministry of Higher Education (MoHE) Malaysia through Fundamental Research Grant Scheme (FRGS/1/2017/TK10/ UTAR/02/5). The authors thank to the Universiti Tunku Abdul Rahman Research Fund (UTARRF) Top Up Scheme (Vote Number 6235/L06). Besides, the authors also thank the Department of Mechanical and Material Engineering as well as Department of Laboratory Management and Safety Administration under Lee Kong Chian Faculty of Engineering and Science (LKCFES), Universiti Tunku Abdul Rahman for the research facilities allocation. Finally, the authors extend their gratitude to Malaysian Nuclear Agency for the Raman spectroscopy analysis services.

\section{Authors' contributions}

Investigation, data curation, writing - original draft, writing - review \& editing, A.C.W.Y; conceptualization, methodology, investigation, writing - review \& editing, funding acquisition, supervision, H.S.L.; investigation, resources, J.L.L; investigation, resources, N.S.M. All authors read and approved the final manuscript.

\section{Funding}

This research was supported by Ministry of Higher Education (MoHE) Malaysia through Fundamental Research Grant Scheme (FRGS/1/2017/TK10/ UTAR/02/5) and Universiti Tunku Abdul Rahman Research Fund (UTARRF) Top Up Scheme (Vote Number 6235/L06).

\section{Availability of data and materials}

All data generated or analyzed during this study are available from the corresponding author upon request.

\section{Competing interests}

The authors declare they have no competing interests.

\section{Author details}

${ }^{1}$ Department of Mechanical and Material Engineering, Universiti Tunku Abdul Rahman, 43000 Kajang, Malaysia. ${ }^{2}$ Centre for Photonics and Advanced Materials Research, Universiti Tunku Abdul Rahman, 43000 Kajang, Malaysia. ${ }^{3}$ Department of Mechatronics and Biomedical Engineering, Universiti Tunku Abdul Rahman, 43000 Kajang, Malaysia. ${ }^{4}$ Department of Civil Engineering, University of Malaya, 50603 Kuala Lumpur, Malaysia.

Received: 19 October 2020 Accepted: 28 January 2021

Published online: 10 February 2021

\section{References}

1. Omer NH. Water quality parameters. In: Summers JK, editor. Water quality science, assessments and policy. London: IntechOpen Limited; 2020. p. 320.

2. loka S, Muraoka H, Matsuyama K, Tomita K. In situ redox potential measurements as a monitoring technique for hot spring water quality. Sust Wat Resour Man. 2016;2:353-8.

3. Walczak MM, Dryer DA, Jacobson DD, Foss MG, Flynn NT. pH-dependent redox couple: illustrating the Nernst equation using cyclic voltammetry. J Chem Educ. 1997;74:1195-7.

4. Clark LC, Wolf R, Granger D, Taylor Z. Continuous recording of blood oxygen tensions by polarography. J Appl Physiol. 1953;6:189-93.

5. Wei YG, Jiao YS, An D, Li DL, Li WS, Wei Q. Review of dissolved oxygen detection technology: from laboratory analysis to online intelligent detection. Sensors-Basel. 2019;19:3995.

6. Santhosh C, Velmurugan V, Jacob G, Jeong SK, Grace AN, Bhatnagar A. Role of nanomaterials in water treatment applications: a review. Chem Eng J. 2016:306:1116-37.

7. Cheng Y, Jiang SP. Advances in electrocatalysts for oxygen evolution reaction of water electrolysis-from metal oxides to carbon nanotubes. Prog Nat Sci-Mater. 2015;25:545-53.

8. Lee HS, Yap ACW, Ng CC, Mohd NS, Loo JL. Increased electron density and dissolved oxygen level in water through magnetic effect. In: 9th International Conference on Future Environment and Energy. Osaka; 2019 Jan 9-11.

9. Yap ACW, Lee HS, Loo JL, Mohd NS. Investigation of the magnetic effects on water properties using permanent magnets. In: 3rd International Symposium Green and Sustainable Technology. Kampar; 2019 Apr 23-26.

10. Hassan SM, Rahman RA. Effects of exposure to magnetic field on water properties and hatchability of Artemia salina. ARPN J Agric Biol Sci. 2016;11: 416-23.

11. Yin J, Zhang JK, Wu L, Li X. Influence of water physical and chemical performance by magnetizing. Adv Mater Res. 2011;281:223-7.

12. Chen HC, Mai FD, Hwang BJ, Lee MJ, Chen CH, Wang SH, et al. Creation of electron-doping liquid water with reduced hydrogen bonds. Sci Rep-UK. 2016;6:22166.

13. Kai T, Yokoya A, Ukai M, Fujii K, Watanabe R. Dynamic behavior of secondary electrons in liquid water at the earliest stage upon irradiation: implications for DNA damage localization mechanism. J Phys Chem A. 2016;120:8228-33.

14. Zilio P, Dipalo M, Tantussi F, Messina GC, de Angelis F. Hot electrons in water: injection and ponderomotive acceleration by means of plasmonic nanoelectrodes. Light-Sci Appl. 2017;6:e17002.

15. Mansor MSAC, Amir MNI, Julkapli NM, Ma'amor A. Gold hybrid nanomaterials: prospective on photocatalytic activities for wastewater treatment application. Mater Chem Phys. 2020;241:122415.

16. Mulpuri RK, Tirukkovalluri SR, Imandi MR, Alim SA, Kapuganti VDL. Zinc and boron co-doped nanotitania with enhanced photocatalytic degradation of Acid Red 6A under visible light irradiation. Sustain Environ Res. 2019;29:29.

17. Chen KT, Bai MD, Yang HY, Chen YC, Lu WJ, Huang CP. Removal of ammonia from leachate by using thermophilic microbial fuel cells equipped with membrane electrode. Sustain Environ Res. 2020;30:5.

18. Sasikala SP, Nibila TA, Babitha KB, Mohamed AAP, Solaiappan A. Competitive photo-degradation performance of $\mathrm{ZnO}$ modified bentonite clay in water containing both organic and inorganic contaminants. Sustain Environ Res. 2019;29:1.

19. Toledo EJL, Ramalho TC, Magriotis ZM. Influence of magnetic field on physical-chemical properties of the liquid water: insights from experimental and theoretical models. J Mol Struct. 2008;888:409-15.

20. Silva IB, Neto JCQ, Petri DFS. The effect of magnetic field on ion hydration and sulfate scale formation. Colloid Surface A. 2015;465:175-83. 
21. Chibowski E, Szczes A. Magnetic water treatment - a review of the latest approaches. Chemosphere. 2018;203:54-67.

22. Gabrielli C, Jaouhari R, Maurin G, Keddam M. Magnetic water treatment for scale prevention. Water Res. 2001;35:3249-59.

23. Kim S, Kim KH. Effect of magnetic field arrangement of facing targets sputtering (FTS) system on controlling plasma confinement. Coatings. 2020; 10:321.

24. Lin L, Jiang WB, Xu XS, Xu P. A critical review of the application of electromagnetic fields for scaling control in water systems: mechanisms, characterization, and operation. Npj Clean Water. 2020;3:25.

25. Alabi A, Chiesa M, Garlisi C, Palmisano G. Advances in anti-scale magnetic water treatment. Environ Sci-Wat Res. 2015;1:408-25.

26. Chibowski E, Szczes A, Holysz L. Influence of magnetic field on evaporation rate and surface tension of Water. Colloid Interfac. 2018;2:68.

27. Kadhim KN, Al-Rufaye AHR. Experimental study of magnetization effect on ground water properties. Jordan J Civ Eng. 2018;12:254-62.

28. Wahid ZA, Othman F, Sohaili J. Electromagnetic technology on sewage treatment. Malays J Civ Eng. 2001;13.

29. Kramer M. The DC motor. 2012. http://large.stanford.edu/courses/2012/ph24 0/kramer2/. Accessed 24 Oct 2020.

30. Klempner G, Kerszenbaum I. Handbook of large turbo-generator operation and maintenance. Hoboken: Wiley; 2008.

31. Perlt E, von Domaros M, Kirchner B, Ludwig R, Weinhold F. Predicting the ionic product of water. Sci Rep-UK. 2017;7:10244.

32. Le Chatelier HL. On a general statement of the laws of chemical equilibrium. C R Acad Sci Paris. 1884:99:786-9 [in French].

33. Dasmeh P, Searles DJ, Ajloo D, Evans DJ, Williams SR. On violations of Le Chatelier's principle for a temperature change in small systems observed for short times. J Chem Phys. 2009;131:214503.

34. Ntella SL, Stradolini F, Tuoheti A, Demarchi D, Hatzopoulos AA, Carrara S. Architecture and procedures for $\mathrm{pH}$ and temperature monitoring in medical applications. In: 2017 IEEE SENSORS. Glasgow; 2017 Oct 29-Nov 1.

35. Gatemala H, Ekgasit S, Pienpinijtham P. 3D structure-preserving galvanic replacement to create hollow Au microstructures. Cryst Eng Comm. 2017;19: 3808-16.

36. Bratsch SG. Standard electrode potentials and temperature coefficients in water at 298.15 K. J Phys Chem Ref Data. 1989;18:1-21.

37. Jerkiewicz G. Standard and reversible hydrogen electrodes: theory, design, operation, and applications. Acs Catal. 2020:10:8409-17.

38. Li RH, Jiang ZP, Guan YT, Yang HW, Liu B. Effects of metal ion on the water structure studied by the Raman O-H stretching spectrum. J Raman Spectrosc. 2009:40:1200-4.

39. Pang XF, Deng B. The changes of macroscopic features and microscopic structures of water under influence of magnetic field. Physica B. 2008;403: $3571-7$.

40. Duenas JA, Weiland C, Nunez MA, Ruiz-Rodriguez FJ. Effect of low intensity static magnetic field on purified water in stationary condition: ultraviolet absorbance and contact angle experimental studies. J Appl Phys. 2020;127: 133907.

41. Hao S, Li H, Li X, Li L, Xie J. Effect of impurity content on structure of living water. J Water Chem Technol. 2016;38:158-62.

42. Wu J. Tackle the free radicals damage in COVID-19. Nitric Oxide. 2020;102: 39-41.

43. Perillo B, Di Donato M, Pezone A, Di Zazzo E, Giovannelli P, Galasso G, et al. ROS in cancer therapy: the bright side of the moon. Exp Mol Med. 2020;52: 192-203.

44. Lopez-Lazaro M. Role of oxygen in cancer: looking beyond hypoxia. AntiCancer Agent Me. 2009;9:517-25.

45. Feng LZ, Betzer O, Tao DL, Sadan T, Popovtzer R, Liu Z. Oxygen nanoshuttles for tumor oxygenation and enhanced cancer treatment. CCS Chem. 2019;1:239-50.

\section{Publisher's Note}

Springer Nature remains neutral with regard to jurisdictional claims in published maps and institutional affiliations.

\section{Ready to submit your research? Choose BMC and benefit from:}

- fast, convenient online submission

- thorough peer review by experienced researchers in your field

- rapid publication on acceptance

- support for research data, including large and complex data types

- gold Open Access which fosters wider collaboration and increased citations

- maximum visibility for your research: over $100 \mathrm{M}$ website views per year

At $\mathrm{BMC}$, research is always in progress.

Learn more biomedcentral.com/submissions 